\title{
Delivery Pain Anxiety/Fear Control between Midwives among Women in Cross River State, Nigeria
}

\author{
Oyira, Emilia James ${ }^{1}$, Mgbekem Mary ${ }^{1}$, Osuchukwu, Easther Chukwudi ${ }^{1}$, Affiong Ekpenyong Onoyom ${ }^{2}$, Lukpata, \\ Felicia E. ${ }^{1}$, Ojong-Alasia Mary Manyo ${ }^{3}$ \\ ${ }^{1}$ Department of Nursing Science, University of Calabar, Calabar-Nigeria \\ ${ }^{2}$ School of Health Technology Calabar, University of Calabar, Cross River State-Nigeria \\ ${ }^{3}$ Department of Nursing, Madonna University, Nigeria
}

Correspondence: Oyira, Emilia James, Department of Nursing Science, University of Calabar, Calabar-Nigeria

Received: July 21, 2015 Accepted: September 8, 2015 Online Published: January 30, 2016

doi:10.11114/jets.v4i3.1346 URL:http://dx.doi.org/10.11114/jets.v4i3.1346

\begin{abstract}
Objective: To examine background of midwives the effectiveness in delivery pain and anxiety/fear control of expectant mothers in Nigeria. Methods: Two null hypotheses were formulated. The survey design with sample of 360 post-natal women was selected from a population of 78,814 through the polio immunization registers of selected health center in cross river states. Accidental sampling technique was used to select the respondents. The instrument used for collecting data for the study was a 36-item questionnaire. Independent t-test and contingency chi-square were used in testing the null hypotheses. Results: The result showed that women delivered by traditional midwives have more positive control of delivery pain caused by anxiety/fear than their counterparts who delivered by the western midwives; Conclusion: Based on these finding the study concluded that traditional midwives are actually different from their counterparts. All what they need is workshops, seminar, conferences during ante-natal period to acquaint the traditional midwives with delivery related activities and procedures. It was also recommended that the traditional midwives should be given adequate western training so that they can face the society and avoid further complications. Government should continue to train more midwives to help reduce the anxiety/fear state of women during delivery.
\end{abstract}

Keywords: background of midwives, delivery pain anxiety/fear control, postnatal women

\section{Introduction}

\subsection{Background to the Study}

In contemporary Nigeria society today, the birth of a baby is a momentous occasion. The details of the experiences surrounding the whole event are etched on one's memory forever. Delivery pain is a global phenomenon experienced by every woman going through child birth. This places huge responsibility on midwives in both urban and rural communities in helping women through child delivery and are recognized worldwide in that capacity. The western midwife holds the key in promoting the antenatal and post-natal health and well-being of childbearing women and their families (Cooper, 2003). Traditional midwives do the same However, since they have no formal training on how to carry out their operation; they indulge in old methods of delivery. Many women suffer complications under them. They suffer maternal and foetal complications even when the western midwives lacks good behaviour (Aldrich \&Eccleston 200).They lacks spiritual backup support in their environment, expensive bills, unnecessary protocols, job stress with a large number of patients can no longer meet up with the demands and the need of patients resulting to lack of interest and care to the patients. But this can be control because of adequate facilities found in the hospital which the traditional midwives lack (Cheung, 1994).

Pain delivery control is the way individuals or groups of midwives manage their clients in pain. Kitzinger (1987) States that the way an individual perceives and reacts to delivery pain is affected by different factors e.g. fear anxiety, depression, personality, fatigue, age, socio-cultural factor and previous experiences etc.

Delivery pain is a peculiar experience that can only be well explained by women who had passed through child birth experience. Each woman describes it in her own peculiar way depending on the pain threshold. Some feel it as waist 
pain resulting in constant urination and later into 30 minute interval pain just around the waist and as it progresses, the cervix becomes dilated and baby is born, while others have sudden delivery with less pain (Bannerman, 1982).

Experiences have shown that many women prefer going to traditional midwives than the hospital. Reasons are ascribed to time wasting, payment of bills, and lengthy "unnecessary" protocols. Apart from this, some women/relatives feel that some western midwives have very unfriendly attitude which can cause spontaneous abortion. Besides, when the client is due for delivery she must have to produce all necessary papers to prove that she has been consulting in that health center for the past six months. Even when this is done, there is always payment required before anything is done. Ihejiamaiz (2002) asserted that while traditional midwives help mothers to wash napkins, hospital midwives won't have such time reducing their level of anxiety. All these make traditional midwives to win the confidence of women both in urban and rural areas. The understanding of the rural women in particular about the hospital is that it is a place for educated people and those who have money (Shilling, 2000).

Moreso, it is a place where surgical operations are carried out hence they hate it. Any mention of going to hospital no matter how critical their condition may be, radiate fear, anxiety; which could lead to psychological state of depression. This may result in serious shock as well as death for fear of likely surgery and complications. This scares them and open ways for traditional midwives. In some communities, traditional midwives are full-time health workers who expect to be paid either in cash or in kind. In continents like Asia and Europe etc have started training traditional midwives in descents and healthy environment.Non-governmental societies have invested their resources by educating the traditional midwives concerning risk associated with birth with the expectation that traditional midwives would help reduce maternal mortality in Nigeria (Calister, \&Vage, 1998).

Government on their own part have tried as much as possible to train the western midwives whose responsibilities are to diagnose and monitor pregnancies, labours, and post partum progress, to work with child bearing women and other health care professional to achieve the best possible outcome for each individual family. The heads of department in the hospitals on their own part now being worried about most midwives attitude, try to organize continuing education to train the western midwives on their attitude towards their clients to reduce anxiety during delivery. Be that as it may majority of trained midwives are still showing negative attitude towards their clients (Kitziger, 1987).

Some women prefer going to traditional midwives because of the following reasons: proximity, religious reason, social reason, economic reason and socio-cultural reasons.

Observation shows that women who are tense and anxious impede the progress of labour, while for those who are relaxed; labour becomes quicker and less painful. A tense pelvic floor might delay delivery. However, women who relax completely and rest in between pains conserved their energy and it will help them face the second stage of labour pain with ease. Traditional midwives cannot be patient enough; they would rather hasten labour even when the cervix is not fully dilated. Sometimes, the outcome of it results into death. This study is therefore being carried out as an effort to help the health care system solve the problem of negative control of delivery pain anxiety/fear among women. The study is directed at determining the difference between women who delivered through trained midwives and those delivered through traditional midwives in their control of anxiety/fear among women.

\subsection{Importance}

The significance of the study is to help both midwives make out time for better services be patience during delivery to allay women of their anxiety/fear in labour/ delivery. The study adds to increasing volume of knowledge about midwives differences on delivery pain anxiety/fear control and is expected to generate debates and discussions which might go a long way towards increasing understanding of chosening a better place of delivery both at home and hospital among postnatal women.

\subsection{Goals}

Our goal is to make sure that women during delivery are better allayed of delivery pain anxiety/fear before labour beings. The women will be courageous and feel relax during labour believing that it is a natural phenomena.

\section{Review of Related Literature}

\subsection{Control of Women towards Birth Pain Caused by Anxiety by both Western and Traditional Midwives}

Control of women birth pain anxiety by western and traditional midwives childbirth is very stressful both at home and hospital. Midwives are recognized as the experts and lead caregivers in normal child birth, but this is not as simple as it sounds. Alongside they move to provide women with more choice, control and continuity is the debate about what is normal and how much choices should be available to women in resources limited National Health Services (Walsh, 2000).

Midwives need to be aware of the legislation and guidelines defining their roles, describing their scope of practice and 
specifying standard of competence (Walsh, 2000). Society is composed of people from many facets and background. Caregivers must be efficient, fair and without prejudice. Where midwives find that, they do not have the skills or expertise to provide effective care for individuals or groups then they need to seek assistance. Midwives should strive for continuous improvement and service excellence in midwifery practice.

Midwife means "with women, and in France, it mean wise woman." Contemporary studies showed that woman have often relied on trained or traditional caregivers.

In past, men were excluded from the birthing room, being allowed in only once the baby was born. Now pregnant women are encouraged to choose a birth partner, male or female to support them in labour. Midwives have, therefore, to develop their skills of being with women to include and involve the woman's chosen birth partner. At times this requires the midwife to stand back, observe, listen and intervene only when invited to do so or when it is in the best interests of the woman, foetus or baby. At other times, the midwife will need to ensure that the woman's partner is appropriately informed about child birth so that, they can make sound decisions together. On occasions the midwife might need assistance when the partner's/friend's/relative's actions are unlikely to enhance, or could harm the health and safety of mother and child (Webber, 1996).

Traditional midwives are the reverse of trained midwives. They lack full knowledge of home delivery and hospital delivery, complications and the risk of birth, and also standard of care giving before, during and after delivery.

Chachukwu,(1991) further state that in some countries, formal programmes have been devised for further training of these traditional midwives and for incorporating them within the health services. In favour of such schemes, that these attendants usually belong to the local community in which they practice, where they have gained the confidence of the families and where they continued to live and serve.

In Nigeria, traditional midwives assist tremendously especially in developing countries of the world were especially in the remote areas where health manpower is still lacking Chachukwu, (1991).

Nigeria has shortages of skilled birth attendants particularly midwife that are also unevenly distributed. The result is that majority of our women deliver at home. The cares rendered by traditional midwives are pre-postnatal care and preventive care. From the foregoing, it becomes pertinent to know the care rendered or propounded by traditional birth attendants in our communities. In Nigeria, traditional midwives Examples include herbalists, traditional midwives, traditional surgeons, etc.These practices are not indoubt,but what may be question is whether they are systematic, that is organized, and clinical.

\subsection{Educational Level of Post-natal Women and Their Place of Delivery}

Lack of education and awareness on the existence of the policy on the use of ante-natal clinics by rural pregnant women appears to increase the probability of mortality among them. Equally, Bates, (1987) reveals that people of higher socio-economic status and educational level tend to prefer modern medicine or hospital during ill health as against the low income group with no education. Patients who are only half convinced of the values of hospitals and their specialized services are the ones most likely to attend hospital irregularly (Bates, (1987).

Bates, (1987) reveals that there is a strong relationship between the opinion of the literate and the non-literate women about the factors preventing pregnant women from making use of health services. For one thing, education has seriously changed some of the cultural beliefs of women in the rural areas about the use of health services. On the other hand, women who lack information on the use of health services could receive information from the few who are aware of the values of hospitals or the presence of clinics around them may motivate them to visit or make adequate use of health services. Another factor responsible for the non-utilization of health services is said to be the distance of hospital or clinics from homes Bates, (1987). Patient without adequate transportation system either resort to trekking long distances or are completely discouraged from making use of the facilities or services. Bates, (1987) say demographic characteristics such as income may have influence on one's behaviour. This goes to support (Chachukwu, 1991 Bannerman, 1982, Aldrich, \& Eccleston, 2000) are of the view that people with high educational standards tend to patronize health services or modern facilities to the best advantage as against the less educated.

Low income earners cannot have any access to health care services. These draw back gave the impetus for primary health care (PHC) health care. WHO, (1992) Agrees with Chachukwu, (1991) that in some developing countries like Nigeria, modern medical service has been received by few people in their rural communities. He attributes factors like lack of money, old traditions and taboos to be responsible for the lack of orthodox medical care of which ante-natal care is part.

Chachukwu,(1991) Observed that some of the reasons for this preference are lack of information about health facilities and the perceived inconveniences involved in going to the hospital. On the factors that could be responsible for most pregnant women in the rural areas not making use of health services, Chachukwu, (1991) observes lack of money as the 
most influential factor, followed by ignorance and lack of time. This supports WHO, (1992) and Chachukwu, (1991) that had a similar view.

Insufficient infrastructural network, are some of the factors militating against rural pregnant women patronzing modern medical facilities. Shortage of transport is mentioned as a serious obstacle. This shortage has forced rural pregnant women to opt for alternative means of transport such as walking long distances which affect their health and that of the unborn baby.

If a facility has an ambulance, it usually serves multiple purposes and may not be available at certain times. Lack of fuel for the ambulance was also a factor against utilization of health care services. Chachukwu, (1991) also agrees that socio-economic status play a great role in improving health situations and consequently, lack of socio-economic development may lead to negative outcome of health care systems or strategies available to the rural pregnant women. According to him, a two way path relationship is known to exist between health status of the citizen and the general socio-economic development of the nation. But the actual impact of development of the community will solely rely on the level of health education attained about the use of health services and the degree of utilization of these health facilities within the rural communities (Bannerman, 1982).

Adejumo, (1982) posits that socio-economic development enables the health programme to focus on the mother in enhancing the knowledge of maternal and childcare services, thereby reducing the number of people at the highest risk. She does tend to attend ante-natal, clinics more than those with lower socio-economic status. Accordingly, Webber, (1994) has emphasized that improvement in the health status of a population cannot, however, be achieved simply by expanding and developing the health services.

Pregnant women and nursing mother's hazards are higher in women from lower socio-economic groups because their socio-economic status determines their motivational habits. Thus, a combination of being unemployed, without access to recreational sports and a limited food of poor nutritive values Cooper, (2003) have a summary of demographic data and conclude that the most handicapping and most disabling condition in childhood is poverty itself. Those most affected are those of the low income group that live in the ghetto, rural areas and large facilities headed by parents of low educational achievement. Being poor, uneducated and a member of minority group increases substantially the possibility of having a complication during pregnancy in general and a low birth weight in particular Crafter, (1992) and WHO, (1992) as cited by Chapman, (2000) they have further observed that socio-economic status affects habits and body size as well as attitudes towards feeding. Families in the high income group have $9 \%$ incidence of poor diet, families in the middle income group have an incidence of 36\% poor dieting (Crafter, 1992). Thus lack of adequate education and poor socio-economic status contribute immensely to pregnant women in rural areas not making adequate use of health services for delivery. Maternal mortality accounts for a large proportion of the death occurring among women of child bearing age in most of the developing world. Each year about half a million women die from cause related to pregnancy and child birth and 1990 of these deaths occur in developing countries (WHO, 1991). International concerns over this appalling situation have greatly increased in recent years and have been emphasized in conclusion and recommendations of both the international conference on population in 1984, and the achievements of the United Nation Decade for Women in 1985. A major international meeting the safe motherhood conference, held in Nairobi 1987 was also devoted to the subject WHO (1991) recently intensified its efforts to improve maternal mortality. With the support of United Nation Population Fund, (UNDP) World Health Organization (WHO) initiated a World- wide programme on the collection, analysis and dissemination of information on maternal mortality and on the improvement and extension of coverage of maternal health care. As part of this programme, a WHO interregional meeting on prevention of maternal mortality was held in Geneva in 1985. Experts from many parts of the developing world received the result of more than 20 studies on maternal mortality from all regions of the world.

They then considered the medical, health services, reproductive and socio-economic factors responsible for the very high maternal death rates in developing countries. Again, the ever rising cost of technical care was made available mainly to the rich and the middle income.

\subsection{Place of Birth}

Does the place of birth have an impact on the course of labour and delivery? This question has been abundantly researched in the past two decades (Callister, \& Vega, (1998), when in many developed countries labour went from a natural process to a controlled procedure, the place of birth changed from home to hospital. At the same time much of the human touch was taken out. Pain was alleviated pharmacologically and women were left alone for long periods of time as they were in a light sleep anyway; they were monitored closely from afar. This was the opposite end of the spectrum of those parts of the world where fewer than $20 \%$ of women have access to any type of formal birth facility. For them, home birth is not an option, it is virtually inevitable, for reasons ranging from the economic to the cultural, and including the geographical (Shilling, 2000; Webber, 1996; Walsh, 2000). The call for a return to the natural process 
in many parts of the developed world opened up delivery rooms to fathers and to other family members, but the location stayed the same: the hospital. Some hospitals have made an effort by installing a home-like birth room and this was found to increase maternal satisfaction and reduce the rate of perineal trauma, as well as reducing the desire for a different setting for the next birth, but randomized trials found no effect on the use of epidureal analgesia, forceps delivery and caesarean section (Collen, 2006; Chapman, 2000. These trails were primarily concerned with a more attractive labour ward setting without a fundamental change in care; apparently this is not enough to improve the quality of care and the obstetric outcome.

Other studies found that a woman with a low-risk delivery giving birth to her first child in a teaching hospital could be attended by as many as 16 people during 6 hours of labour and still be left alone for most of the time (Halldorsdother, \& Karidottir, 1996). Routine, though unfamiliar, procedures, the presence of strangers and being left alone during labour and/or delivery caused stress, and stress can interfere with the course of birth by prolonging it and setting off what has been described as a "cascade of intervention".

Home birth is a practice which is unevenly spread across the world. With the widespread institutionalization of childbirth since the 1930s the option of a home birth in most developed countries disappeared, even where it was not banned. The system of obstetric care in the Netherlands, where still more than 30\% of pregnant women deliver at home, is exceptional among developed countries (Collen, 2006; Dreamoni, 2006). On the other hand, in many developing countries, great distances between women and the health facilities restrict options and make home birth the only choice.Often, high and very high risk women do not feel ill or show signs of disease, so they give birth at home, attended by a family member, by a neighbour or by a traditional birth attendant (Collen, 2006).

However, a properly attended home birth does require a few essential preparations. The birth attendant must make sure that there is clean water at hand and that the room in which birth takes place is warm. There is a need for careful hand washing. Warm clothes or towels must be ready to wrap the baby to keep it warm. There must also be at least some form of clean delivery kit as recommended by WHO in order to create as clean field as possible for birth and to give adequate treatment to the umbilical cord. Furthermore, transport facilities to a referral centre must be available if needed. In practical terms this means that community participation and revolving funds are necessary to enable transport to be arranged for emergencies in areas where transportation is a problem.

In some developed countries birth centres in and outside hospitals have been established where low-risk women can give birth in a home-like atmosphere, under primary care, usually attended by midwives. In most such centres electronic fetal monitoring and augmentation of labour are not used and there is a minimum use of analgesics. An extensive report about birth centre care in the USA described care in alternative birth centres in and outside hospitals (Dreamoni, (2006). Experiments with midwife-managed care in hospitals in Britain, Australia and Sweden showed that women's satisfaction with such care was much higher than with standard care. The number of interventions was generally lower, especially obstetric analgesia, induction and augmentation of labour. The obstetric outcome did not significantly differ from consultant-led care, though in some trials perinatal mortality tended to be slightly higher in the midwife-led models of care (Halldorsdother, \&Karidottir, 1996).

In a number of developed countries dissatisfaction with hospital care led small groups of women and caregivers to the practice of home birth in an alternative setting Statistical data about these home births are scarce. In an Australian study data were collected which suggested that the selection of low-risk pregnancies was only moderately successful. In planned home deliveries the number of transfers to hospital and the rate of obstetric interventions were low. Perinatal mortality and neonatal morbidity figures were also relatively low, but data about preventable factors were not provided (Callister, \& Vega, (1998).

A study conducted in the province of Gelderland, compared the "obstetric result" of home births and hospital births. The result suggested that for primiparous women with a low-risk pregnancy a home birth was as safe as a hospital birth. For low-risk multiparous women the result of a home birth was significantly better than result of a hospital birth (Collen, 2006). There was no evidence that the system of care for pregnant women can be improved by increasing medicalisation of birth (Colleen, 2006).

In Nepal the decentralization approach of maternity care has been adapted to the special needs of urban areas in a developing country, where a hospital's capacity to deliver the specialist obstetric services needed by women with childbirth complications was being swamped by the sheer number of low-risk women experiencing normal birth-a common scenario in many countries. The development of a "low-technology" birthing unit in the vicinity of the main hospital not only took the pressure of the specialist unit birth made it much easier to deliver appropriate care to women in normal labour. The care of high-risk women in the hospital was improved by the reduction in numbers of low-risk women, while in the peripheral units time was available to ensure that the low-risk women received the care and attention they needed (Collen, 2006). 
So where then should a woman give birth? It is safe to say that a woman should give birth in a place she feels is safe, and at the most peripheral level at which appropriate care is feasible and safe (FIGO, 1992). However, it must be a place where all the attention and care are focused on her needs and safety, as close to home and her own culture as possible, if birth does take place at home or in a small peripheral birth centre, contingency plans for access to a properly-staffed referral centre should form part of the antenatal preparations.

\section{Methods}

The focus of methods in this study will be on the research method under the following sub-headings:

\subsection{Research Design}

In a survey design, according to Isangedighi, Joshua, Asim, \& Ekur (2004) the researcher attempts to obtain a picture of the present conditions of particular phenomena, and depends basically on questionnaires and interviews as means of data collection.

This particular design identifies variables under investigation and are examined as they existed when the study was carried out. The study also involves very large populations that were only covered through a sample using questionnaires and describing the picture of the situation instead of drawing inference, (Isangedighi, Joshua, Asim, \& Ekur, 2004)

In this study, the independent variables, trained midwives and traditional midwives, was a measure of differences; while dependent variables already exist in the control of anxiety/fear of women.

\subsection{Research Area}

The area covered by this study is Cross River State of Nigeria. Cross River State is located in the South Eastern flank of the Federal Republic of Nigeria in what is known as the south-south zone, between latitude $5^{0} 32$ and $4^{0} 27$ north of the equator, and longitude $7^{0} 50$ and $9^{0} 28$ east of the Greenwich meridian.

Cross River State as it exists today consists of eighteen (18) local government areas According to the state ministry of lands and surveys, the state occupies a land mass of 23,074, 425 square kilometers and is accessible by road, air and water. The study area was chosen because women complained of anxiety/fear control during delivery and the researcher decides to know the differences that exist between midwives.

\subsection{Research Population}

The population of this study is made up of all post-natal women in Cross River State, who have their names registered as mothers into the state polio immunization registers in 2009. The comprehensive registers available at all local government health centers with the state show that there were a total of $(78,814)$ Seventy-eight thousand, eight hundred and fourteen postal-natal women in the state during the period. A break-down of the population figure is shown in the Table 1.

\subsection{Sampling Procedure}

Two sampling techniques were adopted in selecting the sample for the study. These are the simple random and accidental sampling techniques. The former was used in selecting equal number of Local Government Areas (LGAs) for the study from each of the three Federal Senatorial constituencies Districts. Four LGAs in Southern District, three from the central and two from the northern senatorial districts. From each Local Government Area 40 respondents were used for the study.

To carry out the selection of health centres all the names of the centres in each Local Government Areas were written down on a piece of paper and then subjected to selection through simple random sampling technique of the fact that all health centres have polio immunization registers with the addresses of contact families in them. The post-natal women were reached through the polio immunization registers of the selected health centres. 
Table 1. Study population by senatorial district and local government area

\begin{tabular}{llr}
\hline SENATORIAL DISTRICT & \multicolumn{1}{c}{ LOCAL GOVERNMENT AREA } & $\begin{array}{r}\text { NO. OF } \\
\text { WOMEN }\end{array}$ \\
\hline Southern & Bakassi & 312 \\
& Akpabuyo & 3,358 \\
& Calabar Municipality & 5,051 \\
& Calabar south & 4,972 \\
& Odukpani & 4,215 \\
& Akamkpa & 3,119 \\
& Biase & 6,012 \\
Tentral & Total & $\mathbf{2 7 , 0 3 9}$ \\
& Yakurr & 6,218 \\
& Abi & 4,964 \\
& Obubra & 5,097 \\
& Ikom & 5,136 \\
& Etung & 2,425 \\
& Boki & 5,611 \\
Torthern & Obal & $\mathbf{2 9 , 4 5 1}$ \\
& Obudi & 4,222 \\
& Bekwara & 3,961 \\
& Ogoja & 5,725 \\
& Yala & 3,853 \\
& Total & 4,563 \\
& Grand total & $\mathbf{2 2 , 3 2 4}$ \\
\hline
\end{tabular}

\section{Source: Polio Immunization Register}

The accidental Judgmental sampling was used in selecting women. This technique is normally used for convenience when other techniques seem difficult to apply. A total of 415 post-natal women were reached and administered questionnaires. From this number 360 questionnaire of women who have delivered in only one of government hospital/health centre or traditional delivery home were finally selected as sample.

For this study the researcher visited as many families found in the register as possible until the required number of questionnaires (for both women who delivered in government hospitals/health centres and in the traditional centres) were completed.

\subsection{Sample}

The sample for this study was made up of 360 post natal women selected from nine (9) Local Government Areas across the Districts. 360 women selected, 160 were from the Southern Senatorial District, 120 from the Central Senatorial District and 80 from the Northern Senatorial District.

\subsection{Instrumentation}

The instrument for the study is a 36 item response called control of Delivery Pain Questionnaire (PDPQ). The questionnaire is on personal data and is made up of 7 items. Section B is on control of delivery pain and it is sub-divided into five sub-sections with six items each. The sub-sections are on control of pain from care giving, pain from attitude of midwives, pain from risk and complications, pain from anxiety/fear, physical delivery pain and educational level of post-natal women and their place of delivery.

\subsection{Validation of Instrument}

In order to validate the instrument, control of delivery pain inventory (PDPI) questionnaire copies were presented to the researcher's supervisor and experts in measurement to scrutinize for face validity. Face validity of an instrument is obtained through a superficial examination of content of the research instrument and the establishment of the fact that the content can measure what it wants to measure.

\subsection{Reliability of Instrument}

These determine trail test conducted with group of 50 post-natal women in Akwalbom State. The 50 post-natal women who took part in the study were captured twice during polio immunization week. The researcher employed five health staff who did not take part in the immunization and attached each of them to a team to collect data from mothers as the children were being immunized. This was done twice during two consecutive immunizations.

During the second data collection exercise the employed assistant for the trial test were made to repeat the immunization areas they covered in the first test to ensure that the women who completed the questionnaire in the first visit were spotted and made to complete the same type of questionnaire the second time. The two questionnaire 
responses for the 50 respondents were then used for a test-retest reliability estimate. The results of the estimate are presented in Table 2.

\subsection{Data Collection}

\subsubsection{Procedure for Data Collection}

Instruments were administered by the researchers assisted with some research assistants who specifically briefed on the modalities after hours of training sessions.

Table 2.Test - retest reliability estimates of variables on control of delivery pain among post-natal women $(\mathrm{N}=50)$

\begin{tabular}{|c|c|c|c|c|c|}
\hline Independent Variables & $\begin{array}{l}\text { No. of } \\
\text { items }\end{array}$ & Administration & $\mathbf{X}$ & SD & $\mathbf{R x x}$ \\
\hline $\begin{array}{l}\text { Control of women towards birth pain } \\
\text { caused by anxiety at birth. }\end{array}$ & 6 & $1^{\text {st }} 2^{\text {nd }}$ & $\begin{array}{l}13.07 \\
12.93\end{array}$ & $\begin{array}{l}3.16 \\
3.02\end{array}$ & 0.82 \\
\hline $\begin{array}{l}\text { Educational level of post natal } \\
\text { Women and their choice and place of } \\
\text { delivery. }\end{array}$ & 6 & $\begin{array}{l}1^{\text {st }} \\
2^{\text {nd }}\end{array}$ & $\begin{array}{l}12.96 \\
13.07\end{array}$ & $\begin{array}{l}2.91 \\
2.87\end{array}$ & 0.86 \\
\hline
\end{tabular}

\section{Source: Fieldwork, 2010}

The respondents were visited at their individual homes using the addresses of the polio immunization registers kept at the various health centers.

Literate women were allowed to tick the questionnaires after a thorough explanation of the instructions, while illiterate women were assisted by the researcher or her assistants as the case may be by reading out the items in the language understood by the respondents (using an interpreter). The researcher and her assistant waited at each home and retrieved copies of the questionnaire the very moment they were completed.

\subsubsection{Scoring of the Instrument}

The two sections of the questionnaire were coded separately and scored following a four (4) point Likert scale. Thus, (VSA) to (VSD). The following scores were attached to responses on the side.

$\begin{array}{ll}\text { Response Score } & \\ \text { (VSA)Very strongly agree } & 4 \text { points } \\ \text { (A) Agree } & 3 \text { points } \\ \text { (D)Disagree } & 2 \text { points } \\ \text { (VSD)Very strongly disagree } & 1 \text { point }\end{array}$

Scoring was reversed that were negatively worded with a score of 4 reversed to 1 for a very strongly disagree response and vice versa. The coding schedule for the major variables is presented in Table 3.

\subsubsection{Procedure for Data Analysis}

Ho1: Trained under western education do not differ significantly from women delivered by traditional midwives in their control of delivery pain caused by anxiety/fear at birth.

Independent variable: type of midwife

Dependent variable: control of delivery pain as caused by anxiety/fear at birth.

Test statistic used: independent t-test analysis

Ho2: The educational level of post-natal women and their place of delivery is not significantly related.

Independent variable: educational level of post-natal women

Dependent variable: place of delivery

Test statistic used: contingency chi-square

\section{Result}

\subsection{General Description of Data/Variables}

This section is on the data analysis relevant to the study, presentation of results obtained from the analysis and the discussion of findings. This investigation was on the Western and traditional educational background of midwives and 
delivery pain control. Independent variable, place of delivery is categorized in this study into two, namely; delivery through trained midwives and delivery through traditional midwives. Data for this variable was nominal and was collected through a personal data item in section A of the questionnaire. This item requested respondents to tick $(\sqrt{ })$ who they have experienced child delivery under whether it was under a trained midwife, traditional midwife or under both. No respondent said she had been delivered by both 360 respondents, 221(61.4\%) said they were delivered by trained midwives while 139(38.4\%) said they were delivered by traditional midwives.

The major dependent variable in the study is control of delivery pain. This dependent variable was considered under two sub-variables, thus; pain from anxiety, level of education and place of delivery. Data for these variables, the data were accordingly coded and analyzed. The summaries of descriptive analyses are presented in Table 4.

\subsection{Hypothesis-by-Hypothesis Presentation of Results}

Table 4.Descriptive analysis of all continuously measured Variables in the study

\begin{tabular}{lllll}
\hline S/NO & \multicolumn{1}{c}{ Variables-control of: } & $\mathbf{N}$ & $\mathbf{X}$ & SD \\
\hline 4 & Pain caused by anxiety/fear & 360 & 20.89 & 2.59 \\
5 & Level of education and place of delivery & 360 & 17.60 & 5.51 \\
\hline 6 & Total control of pain & 360 & 90.63 & $\mathbf{1 5 . 7 8}$ \\
\hline
\end{tabular}

Source: Fieldwork, 2010

Table 5. Independent t-test for influence of western education of midwives on delivery pain control and reduction of anxiety

\begin{tabular}{lcccc}
\hline Variables & N & X & SD & t \\
\hline $\begin{array}{l}\text { Delivery pain control by trained under western education through } \\
\text { reduction of anxiety }\end{array}$ & 221 & 20.19 & 2.887 & 0.216 \\
$\begin{array}{l}\text { Delivery pain control by traditional educational system through } \\
\text { reduction of anxiety }\end{array}$ & 139 & 20.85 & 2.025 \\
\hline
\end{tabular}

significant at $.05 ; \mathrm{df}=358 ;$ critical $\mathrm{t}=1.96$

Source: Fieldwork, 2010

This means that trained midwives do not differ significantly from traditional midwives in their control of delivery pain through reduction of anxiety.

Hypothesis one

The educational level of post-natal women and their choice place of delivery is the Independent variable in this hypothesis, is the educational level of post-natal women while the dependent variable is place of delivery. The two variables were categorical and measured discretely so the test statistic used in analyzing data for this hypothesis was contingency chi-square. The results shows chi-square of 51.702 is greater than the critical chi-square of 7.81 with 3 degrees of freedom. This means that there is an association between the levels of education of post-natal women on their place of delivery.

Table 6. Chi-square analysis of the relationship between educational level of post-natal women and choice place of delivery

\begin{tabular}{|c|c|c|c|c|c|}
\hline \multirow[t]{2}{*}{ Level of educational } & \multicolumn{2}{|c|}{ Place of delivery } & \multirow[t]{2}{*}{$\mathbf{N}$} & \multirow[t]{2}{*}{ Cal X } & \multirow[t]{2}{*}{ df } \\
\hline & Trained midwife & $\begin{array}{l}\text { Traditional } \\
\text { midwife }\end{array}$ & & & \\
\hline No education & 24 & 29 & 53 & $51.702 *$ & 3 \\
\hline Primary education & 20 & 19 & 39 & & \\
\hline Secondary education & 31 & 53 & 83 & & \\
\hline Tertiary & 146 & 39 & 185 & & \\
\hline Total & 221 & 139 & 360 & & \\
\hline
\end{tabular}

*significant at .05 , critical $\mathrm{X}^{2}=7.81$

Source: Fieldwork, 2010

It is observed from the results that more women who had tertiary education delivered under trained midwives than those with secondary, primary or no education. The null hypothesis is by these results, rejected.

\section{Summary of findings}

They could be summarized into two main issues. These are:

1)Trained under western education do not differ significantly from traditional midwives for their control of delivery pain through reduction of delivery pain anxiety.

2)The educational level of post-natal women does not significantly relate with their choice place of delivery. 


\section{Discussion of Findings}

Findings as presented in section have provided valuable insight into some of the perceptual factors about delivery pain among women deliver by trained and traditional midwives. This will further help to control anxiety/fear both at home and hospital.

\subsection{Control of Women towards Delivery Pain Cause by Anxiety/Fear by both Trained Under Western Education and Traditional Educational System}

Finding from this study reveals that child birth both at home and hospital can be very stressful (Cooper,2003).The study also revealed that post-partum predisposition to emotional disorder and depression can be a catastrophic consequence in Nigeria. This finding is interesting in the sense that anxiety prepared somebody for something ahead. Anxiety is found anywhere whether under trained or traditional midwives. Anxiety creates feelings of unease. This finding tends to agree with those of (Chachukwu, 1991). This means that women who are tense and anxious impede the progress of labour, while for those who relaxed,labour becomes quicker and less painful. A tense pelvic floor might delay delivery. However, women who relax completely and rest in between pains conserved their energy and it will help them face the second stage of labour pain with ease. This implies that women who deliver under trained midwives do not differ significantly from women who deliver under traditional midwives in their control about delivery pain caused by anxiety/fear at birth.

Midwives are recognized as the experts and lead caregivers in normal child birth, but this is not as simple as it sounds. Alongside the move to provide women with more choice, control and continuity, is the debate about what is normal and how much choice should be available to women in resources limited National Health Services (Chachukwu, 1991).

In the past men were excluded from the birthing room, being allowed in only once the baby was born. Now pregnant women are encouraged to choose a birth partner, male or female to support them in labour. Midwives have, therefore, to develop their skills of being with women to include and involve the woman's chosen birth partner. At times this requires the midwife to stand back, observe, listen and intervene only when invited to do so or when it is in the best interests of the woman, foetus or baby. At other times the midwife will need to ensure that the woman's partner is appropriately informed about child birth and parenting so that, they can make sound decisions together. On occasions the midwife might need assisstant when the partner's/friend's/ relative's actions are unlikely to enhance, or could harm the health and safety of mother and child Cooper,(2003) Traditional midwives are the reverse of trained midwives. They lack full knowledge of home delivery and hospital delivery, complications and the risk of birth, and also standard of care giving before, during and after delivery.

World Health Organization,(1992) further state that in some countries, formal programs have been devised for further training of these traditional midwives and for incorporating them within the health services. In favor of such schemes, that these attendants usually belong to the local community in which they practice, where they have gained the confidence of the families and where they continued to live and serve.

\subsection{Educational Level of Post-natal Women and Their Choice Place of Delivery}

The result of research finding shows that more women who had tertiary education delivered under trained midwifes than those with secondary, primary or no education. This finding is in lines with WHO, (1992) who concluded that lack of education and awareness on the existence of the policy on the use of antenatal clinics by rural pregnant women appears to increase the probability of mortality among post natal women.

Equally,Adejumo (1982) reveals that people of higher socio-economic status and educational level tends to prefer modern medicine or hospital during ill health as against the low income group with no education patients who are only half convinced of the values of hospitals and their specialized services are the ones most likely to attend hospitals irregularly.

Bates, (1987) eveals that there is a strong relationship between the opinion of the literate and the non-literate women about the factors preventing pregnant women from making use of health services. On the other hand, women who lack information on the use of health services could receive information from the few who are aware of the values of hospitals or the presence of clinics around them may motivate them to visit or make adequate use of health services. Another factor responsible for the non-utilization of health services is said to be the distance of hospital or clinics from homes (Central Bureau of Health Intelligence 2007).Patient without adequate transportation system either resort to trekking long distances or are completely discouraged from making use of the facilities or services. Crafter, (1997) Say demographic characteristics such as income may have influence on one's behavior. This goes to support Bates, (1987) andWHO, (1990) and Bates, (1987) are of the view that people with high educational standards tend to patronize health services or modern facilities to the best advantage as against the less educated.

The second explanation of place of delivery is in lines with Department of Health (1998) who concluded that, place 
of delivery is an important aspect of reproductive health care. This is in line with research hypothesis findings which imply that there is an association between the levels of education of post-natal women on their place of delivery (Oyira, 2009).

\subsection{Summary of the Study}

A high level of negative control of delivery pain has been observed among women and it has become a matter of great concern leading to infant and maternal mortality rate; this study ventured to find out the negative control of delivery pains by women who delivered through trained under western education and traditional educational system.

Delivery pain experienced level of education place of delivery and reduction of delivery fear/anxiety. The focus of this study was all postnatal women. The study area was Cross River State which comprised of 18 Local Government Areas. The population was made up of seventy eight thousand, eight hundred and fourteen $(78,814)$ postnatal women from polio immunization register kept at the various health centers. The sample comprised of 360 postnatal women selected from the polio immunization register at each health centres. Two hypotheses were tested for the study. Data were obtained by means of questionnaires specially developed for the study. Analyses were carried suggested the findings below:

1) Trained midwives under western education do not differ significantly from traditional midwives in their control of delivery pain caused by anxiety/fear at birth. This means this will lay off the anxiety irrespective of where you choose as a place for delivery. This means that trained under western education and traditional midwives do not differ from each other.

2) Educational level of post-natal women and their place of delivery. This means that there is a relationship between the levels of education of post-natal women on their place of delivery. It is observed from the results that more women who had tertiary education delivered under trained midwives than those with secondary, primary or no education at all.

\subsection{Conclusion}

From the research findings, the following conclusion could be made. The quality and quantity of hospital facilities provided in different hospital determine the quality of the job done by the trained under western system. Any midwives with a good control of delivery pain as a mean of achieving the goals of health care delivery system is more likely to show more commitment to delivery process.

Since the traditional midwife is not paid by the government. It is possible that their control of delivery pain would not necessarily affect their performance. Patients cooperate especially when they realize that their midwives have genuine consideration for them.

Lack of praises, reassurance education will increase patient anxiety and fear during delivery process. Giving traditional midwives the privilege of participating in decision making in terms of setting goals or contributing their ideas in decision affecting them, their patients or overall health care delivery system is not a mark of recognition or job efficiency.

\section{References}

Adejumo, M. A. (1982). The pattern of treatment sought by Nigerian community in times of illness: A case study of Oyo Town. Unpublished M.Ed Project. Department of Physical and Health Education, University of Ibandan.

Aldrich, S., \& Eccleston, C. (2000). Making sense of everyday pain. Social Science and Medicine, 50, $1631-1641$. http://dx.doi.org/10.1016/S0277-9536(99)00391-3

Bannerman, R. (1982). A book for midwives. London: Macmillan.

Bannerman, R. H. (1982). Traditional medicine in modern health care. World Health Forum, 3, 8-26.

Bates, M. S. (1987). Ethnicity and pain: A bio-cultural model. Social Science and Medicine, 24, 47-50. http://dx.doi.org/10.1016/0277-9536(87)90138-9

Callister, L. L., \& Vega, R. (1998).Giving birth Guatemala women's voices. Journal of Obstetrics, Gynecologic and Neonatal Nursing, 27, 289-295. http://dx.doi.org/10.1111/j.1552-6909.1998.tb02651.x

Central Bureau of Health Intelligence (2007). Health sector policy options. New York: Central Bureau of Health Intelligence.

Chachukwu, C. C. (1991). Management: Theory and practice. Onitsha: African Feb. Publisher.

Chapman, L. L. (2000). Expectant fathers and labour epidurals. The American Journal of Maternal Child Nursing, 25, 133-138. http://dx.doi.org/10.1097/00005721-200005000-00006 
Cheung, N. F. (1994). Pain in normal labour: A comparison of experience in southern China and Scotland. Midwives Chronicles, 107, 212-216.

Colleen (2006). Neonatal document. Monday April 17, 2006. http://dx.doi.org/10.1002/14651858.CD000007

Cooper, M. A. (2003). Textbook for midwives ( $4^{\text {th }}$ ed.). London: Oxford University Press.

Crafter, H. (1997).Health promotion in midwifery: Principles and practice. London: Arnold.

Department of Health (DOH) (1992). The health of the nation. London: Her Majesty's Stationary Office.

Department of Health (DOH) (1998).Our healthier nation: A contact for health. London: Her Majesty's Stationary Office.

Department of Health (DOH) (1999). Making a difference. Strength: The nursing and midwifery and health visiting contribution to health and health care. London: Department of Health.

Dreamoni, (2006). Neonatal document. Monday April 17, 2006. http://dx.doi.org/10.1002/14651858.CD000007

Halldorsdother, S., \& Karidottir, S. I. (1996). Journeying through labour and delivery controls of women who have given birth. Midwifery Journal, 12, 48-61. http://dx.doi.org/10.1016/S0266-6138(96)90002-9

Humenick (Eds.), Childbirth education: Practice, research and theory. Philadelphia: Saunders, 138-154.

Ihejiamaizu, E. C. (2002). Issues in population policy and health care administration.Calabar: African Scholars Publishers.

Isangedighi, A., Joshua, M., Asim, A., \& Ekuri, E. (2004). Fundamentals of research and statistics in education and social science. Calabar: University of Calabar Press.

Kitzinger, S. (1987).Some women's experiences of epidurals: A descriptive study. London: National Childbirth Trust.

Kitzinger, S. (2000). Some cultural perspective of birth. British Journal of Midwifery, 8(12), 746-750. http://dx.doi.org/10.1111/j.1365-2702.1992.tb00102.x

Oyira, E. J. (2009).Socio-cultural factors influencing umbilical cord management in northern Cross River State of Nigeria. International Professional Nursing Journal, 5(1), 132-142.

Shilling, S. (2000).Cultural perspective on childbearing.In F. H. Nichols and S. S.

Walsh (2000). Evidence-based care series birth environment. British Journal of Midwifery, 8(5), 276-278. http://dx.doi.org/10.12968/bjom.2000.8.5.8131

Webber, S. F. (1996). Cultural aspects of pain in child bearing women. Journal of Obstetrics, Gynecology and Neonatal Nursing, 25, 67-72. http://dx.doi.org/10.1111/j.1552-6909.1996.tb02515.x

World Health Organization (WHO) (1990).Local government focused acceleration of primary health care: the Nigerian experience. Geneva: World Health Organization.

World Health Organization (WHO) (1992).Local government focused acceleration of primary health care: the Nigerian experience. Geneva: World Health Organization.

\section{$(\mathrm{cc}) \mathrm{BY}$}

This work is licensed under a Creative Commons Attribution 3.0 License. 